\title{
Are self-reported gastrointestinal symptoms among older adults associated with increased intestinal permeability and psychological distress?
}

John-Peter Ganda Mall ${ }^{1,2}$, Lina Östlund-Lagerström,2, Carl Mårten Lindqvist', Samal Algilani ${ }^{2}$, Dara Rasoal ${ }^{2}$, Dirk Repsilber ${ }^{1}$, Robert J. Brummer ${ }^{1}$, Åsa V. Keita ${ }^{3}$ and Ida Schoultz $2^{*^{*}}$

\begin{abstract}
Background: Despite the substantial number of older adults suffering from gastrointestinal (Gl) symptoms little is known regarding the character of these complaints and whether they are associated with an altered intestinal barrier function and psychological distress. Our aim was to explore the relationship between self-reported gut health, intestinal permeability and psychological distress among older adults.

Methods: Three study populations were included: 1) older adults with Gl symptoms $(n=24), 2)$ a group of older adults representing the general elderly population in Sweden $(n=22)$ and 3$)$ senior orienteering athletes as a potential model of healthy ageing $(n=27)$. Questionnaire data on gut-health, psychological distress and level of physical activity were collected. Intestinal permeability was measured by quantifying zonulin in plasma. The level of systemic and local inflammation was monitored by measuring C-reactive protein (CRP), hydrogen peroxide in plasma and calprotectin in stool samples. The relationship between biomarkers and questionnaire data in the different study populations was illustrated using a Principal Component Analysis (PCA).

Results: Older adults with GI symptoms displayed significantly higher levels of both zonulin and psychological distress than both general older adults and senior orienteering athletes. The PCA analysis revealed a separation between senior orienteering athletes and older adults with Gl symptoms and showed an association between Gl symptoms, psychological distress and zonulin.

Conclusions: Older adults with Gl symptoms express increased plasma levels of zonulin, which might reflect an augmented intestinal permeability. In addition, this group suffer from higher psychological distress compared to general older adults and senior orienteering athletes. This relationship was further confirmed by a PCA plot, which illustrated an association between Gl symptoms, psychological distress and intestinal permeability.
\end{abstract}

Keywords: Older adults, Gastrointestinal symptoms, Intestinal barrier function, Psychological distress

\footnotetext{
* Correspondence: ida.schoultz@oru.se

${ }^{2}$ Nutrition and Physical Activity Research Centre, Department of Medical

Sciences, Faculty of Medicine and Health, Örebro University, Örebro, Sweden

Full list of author information is available at the end of the article
} 


\section{Background}

In the last decades lifespan has increased dramatically, but even though a longer lifespan is a success story in itself, it cannot be neglected that old age correlates with an increased need for health care [1]. Thus, it is important to identify areas through which a healthy ageing process can be promoted in order to increase the proportion of independent free-living older adults [2]. Gastrointestinal (GI) symptoms are common among older adults. Fifty to seventy \% of older adults report symptoms of constipation [3,4] and 4-14\% experience problems with diarrhoea [5-7]. In addition, older adults suffering from diseases of the digestive system are at risk of a higher total symptom burden. [8]. Moreover, it has been established that a well functioning gut is essential in order for older adults to experience life-satisfaction and meaningfulness in everyday life [9, 10] [11]. Thus, gut health represents an important area through which health and wellbeing might be promoted. In support of this, we recently showed that senior orienteering athletes, a new potential model of healthy ageing, experience less GI symptoms than general older adults [10]. Even though age-associated GI symptoms are common in the older population, knowledge regarding the mechanisms behind these symptoms remains poor. Increased intestinal permeability is a hallmark of many GI diseases [12-14] but has not been investigated in older adults who self-report GI symptoms. The intestinal epithelium is the major interface with the external environment and while absorbing nutrients and water it simultaneously restrict the free movement of luminal material to the underlying mucosa $[15,16]$. A disruption of the intestinal barrier may result in the passage of microbial antigens and toxins [17], and are associated with intestinal inflammation as well as neurological diseases [18, 19]. Furthermore, elevated levels of reactive oxygen species (ROS) (e.g. oxidative stress) have been suggested to drive intestinal inflammation [20]. Understanding the characteristics of GI symptoms in older adults and their underlying pathophysiology is important in order to facilitate diagnosis and treatment. Here, we aim to investigate how self-reported GI symptoms among older adults correlate to plasma zonulin (an indicator of increased intestinal permeability) $[21,22]$ and psychological distress.

\section{Methods}

\section{Study participants}

The study population was comprised of three groups of older adults; individuals suffering from GI symptoms $(n=24)$, senior orienteering athletes $(n=27)$ and general older adults $(n=22)$. The demographic data and recruitment process are outlined in Table 1 . Comorbidities and medications are displayed in Table 2 .

\section{Ethical considerations}

The study obtained ethical approval by the Uppsala Regional Ethics Review Board (Dnr. 2012/309, 2013/37 and 2015/357). All procedures were carried out in accordance with the declaration of Helsinki and written informed consent was acquired from all participants.

\section{Questionnaires}

Gastrointestinal Symptoms Rating Scale (GSRS) was used as an initial instrument to assess and define the degree of GI symptoms (Table 1). Reliability and validity of the GSRS is well documented [23]. The recruitment process was based on the GSRS score for the domains depicting diarrhoea and constipation (average score $\geq 3$ of the domains for diarrhea and/or constipation) as these conditions are two of the most common GI complaints among the elderly $[24,25]$. The Hospital anxiety and depression scale (HADS) is a widely used validated instrument for the evaluation of psychological distress in medical settings, as well as in older adults [26, 27]. The Frändin-Grimby Activity Scale (FGAS) was used to describe the level of physical activity [28]. Questionnaire details can be found in Table 3 .

\section{Biological samples \\ Blood samples}

After an overnight fast, the participants were instructed not to exercise in the morning, before collection of the blood samples. Plasma from senior orienteering athletes was separated using the Ficoll-paque PLUS (GE Healthcare Life Sciences, UK). For older adults suffering from GI problems and general older adults, plasma was separated using standard operating procedures used in the daily routine at the Örebro University Hospital. Blood samples were centrifuged at $2200 \mathrm{~g}$ for $10 \mathrm{~min}$ and plasma was collected in Eppendorf tubes. Blood samples from 10 individuals were collected using both separation procedures and subsequently analysed to evaluate the difference between the two techniques; in the following analyses the difference was controlled for.

Systemic inflammation. C-reactive protein (CRP) is an acute-phase plasma protein and a marker of inflammation. CRP levels were assessed by the highsensitivity immunoturbidimetric assay, CardioPhase ${ }^{\mathrm{TM}}$, and analysed on the ADVIA 1800 chemistry system (SIEMENS Healthcare Diagostics Inc., NY, USA). A normal CRP was defined as $\leq 2 \mathrm{mg} / \mathrm{L}$.

Oxidative stress. Oxidative stress was estimated by the FORT (Free Oxygen Radicals Test) colorimetric assay (Callegari, Parma, Italy), as previously described [29].

Intestinal permeability. To examine zonulin levels in plasma, as an indirect indicator of small intestinal permeability [22], a zonulin ELISA kit was used following 
Table 1 Data for all the descriptive parameters, displayed for all three groups of older adults, presented as median (IQR)

\begin{tabular}{|c|c|c|}
\hline $\begin{array}{l}\text { General older adults }{ }^{a} \\
n=22 \\
\text { Age: } 70(67-72)^{1}\end{array}$ & $\begin{array}{l}\text { Senior orienteering athletes } \\
n=27 \\
\text { Age: } 68(66-71)^{1}\end{array}$ & $\begin{array}{l}\text { Older adults with Gl symptoms } \\
n=24 \\
\text { Age: } 73(69-75)^{\prime} \\
\text { Age at onset of Gl symptoms: } \\
59(47-65)^{\|}\end{array}$ \\
\hline
\end{tabular}

\begin{tabular}{|c|c|c|c|c|}
\hline \multicolumn{5}{|c|}{ - Demographic data - } \\
\hline Female/Male & $11 / 11$ & $12 / 16$ & $18 / 6$ & \\
\hline $\begin{array}{l}\text { Recruitment } \\
\text { method }\end{array}$ & $\begin{array}{l}\text { Advertisement in local } \\
\text { newspaper }\end{array}$ & $\begin{array}{l}\text { Orienteering clubs within the Örebro } \\
\text { County }\end{array}$ & Advertisement in local newspaper & \\
\hline Inclusion criteria & Age $\geq 65$ yrs & $\begin{array}{c}\text { Age } \geq 65 \text { yrs Actively competing in } \\
\text { orienteering }\end{array}$ & $\begin{array}{c}\text { Age } \geq 65 \text { yrs GSRS* diarrhoea/constipation "II } \\
\text { score } \geq 3\end{array}$ & \\
\hline Exclusion criteria & $\begin{array}{c}\text { Diagnosed GI disease Prescribed } \\
\text { inflammatory regulating drugs }\end{array}$ & $\begin{array}{l}\text { Diagnosed GI disease Prescribed } \\
\text { inflammatory regulating drugs }\end{array}$ & $\begin{array}{l}\text { Diagnosed GI disease Prescribed } \\
\text { inflammatory regulating drugs }\end{array}$ & \\
\hline \multicolumn{5}{|c|}{ - Questionnaire data - } \\
\hline GSRS (total score) & $1.5(1.2-2)$ & $1.3(1.1-1.6)$ & $2.6(2.2-3.1)$ & \\
\hline Diarrhoea & $1.3(1-1.4)$ & $1.3(1-1.7)$ & $3.3(1.7-3.8)$ & \\
\hline Constipation & $1.3(1-2.7)$ & $1.3(1-1.7)$ & $3.3(2-4.7)$ & \\
\hline Indigestion & $1.9(1.3-2.6)$ & $1.5(1.25-2)$ & $3(2.3-3.6)$ & \\
\hline Abdominal pain & $1.3(1-1.8)$ & 1 & $2.3(1.7-3.3)$ & \\
\hline Reflux & $1(1-1.5)$ & 1 & $1.5(1-2.5)$ & \\
\hline $\begin{array}{l}\text { HADS* (total } \\
\text { score) }\end{array}$ & $4(1.5-6)$ & $1(0-3)$ & $5(2.5-10.5)$ & $<0.05^{\mathrm{ab}, \mathrm{bc}}$ \\
\hline FGAS* $^{*}$ & $4(3-4)$ & $4(4-5)$ & $4(3-4)$ & \\
\hline \multicolumn{5}{|l|}{ - Biomarker data - } \\
\hline CRP (mg/L) & $0.5(0.2-1.4)$ & $0.9(0.2-1.3)$ & $1.3(0.7-2.2)$ & \\
\hline $\mathrm{H}_{2} \mathrm{O}_{2} \mathrm{mmol} / \mathrm{L}$ & $2(1.7-2.2)$ & $2(1.7-2.4)$ & $2.1(1.8-2.5)$ & \\
\hline $\begin{array}{l}\text { Calprotectin }(\mu \mathrm{g} / \\
\mathrm{g})\end{array}$ & $0(0-35.9)$ & $0(0-102.5)$ & $0(0-65)$ & \\
\hline $\begin{array}{l}\text {-CRP levels }<2 \text { are co } \\
\text { - } \mathrm{Calprotectin} \mathrm{levels} \leq \\
-\mathrm{H}_{2} \mathrm{O}_{2} \mathrm{mmol} / \mathrm{L}<1.75 \\
-\mathrm{H}_{2} \mathrm{O}_{2} \mathrm{mmol} / \mathrm{L} 1.75-2 \\
-\mathrm{H}_{2} \mathrm{O}_{2} \mathrm{mmol} / \mathrm{L} \text { betwe } \\
-\mathrm{H}_{2} \mathrm{O}_{2} \mathrm{mmol} / \mathrm{L} 3.05< \\
{ }^{*} \mathrm{Abbreviations}, \mathrm{GSRS} \\
\geq 8 \text { for either subscale } \\
\mathrm{a}=\text { General populatio } \\
\mathrm{b}=\text { Senior orienteerin } \\
\mathrm{C}=\text { Older adults with } \\
\text { I: age is presented wit } \\
\text { II: median age at onse } \\
\text { III: } p \text {-value generated }\end{array}$ & $\begin{array}{l}\text { onsidered normal } \\
\leq 50 \mu \mathrm{\mu g} / \mathrm{g} \text { are considered normal } \\
\text { indicates no oxidative stress } \\
2.35 \text { indicates intermediate oxidative st } \\
\text { een } 2.36-3.05 \text { indicates oxidative stress } \\
\text { Kindicates strong oxidative stress } \\
\text { : Gastrointestinal symptoms rating sc } \\
\text { indicates a significant level of depre } \\
\text { on of older adults } \\
\text { g athletes } \\
\text { Gl symptoms } \\
\text { ith median and interquartile range (IQ } \\
\text { et of Gl symptoms (IQR) } \\
\text { from pair-wise comparisons using the }\end{array}$ & $\begin{array}{l}\text { tress } \\
\text { ale, FGAS: Frändin-Grimby Activity Scale, } H \text {, }\end{array}$ & IADS: Hospital Anxiety and Depression Scale, a cut & off score of \\
\hline
\end{tabular}

manufacturer's instructions (Cusabio, Baltimore, USA). In brief, plasma was diluted $1: 2$, and added to pre-coated plates in duplicate, together with controls and standards. Primary biotinylated antibody, streptavidin-horseradish peroxidase, tetramethylbenzidine enzyme substrate, and 2 M HCL were subsequently added. Absorbance was measured at $450 \mathrm{~nm}$ in VERSAmax Tunable Microplate Reader (Molecular Devices, San Diego, CA, USA) using Softmax pro 5 (Molecular Devices). The software generated a standard curve based on the standards, from which the concentrations of the samples were calculated. The detection range of the kit was $0.625 \mathrm{ng} / \mathrm{ml}-40 \mathrm{ng} /$ $\mathrm{ml}$, with the lower limit of detection at $0.156 \mathrm{ng} / \mathrm{ml}$ according to the manufacturers information. In addition, the quantification and intra-assay precision (CV\%) was $<8 \%$.

\section{Stool samples}

Material for faecal sample collection was provided together with comprehensive instruction one-week prior to collection. The sample was collected at the participant's home, instantly frozen at $-20{ }^{\circ} \mathrm{C}$ and transported to the laboratory within one week. Samples were stored at $-80{ }^{\circ} \mathrm{C}$ until analysis.

Intestinal inflammation. Faecal calprotectin was measured to assess intestinal inflammation using the 
Table 2 Distribution of comorbidities and medications used within the study groups

\begin{tabular}{|c|c|c|c|}
\hline & $\begin{array}{l}\text { Senior orienteering } \\
\text { athletes }(n=27)\end{array}$ & $\begin{array}{l}\text { General older } \\
\text { adults }(n=22)\end{array}$ & $\begin{array}{l}\text { Older adults with Gl } \\
\text { symptoms }(n=24)\end{array}$ \\
\hline Comorbidities & $\%$ & $\%$ & $\%$ \\
\hline Cardiovascular diseases & 14.8 & 18.2 & 50.0 \\
\hline Gut symptoms & 11.1 & 22.7 & 100.0 \\
\hline Psychological \& neurodegenerative morbidities & 3.7 & 13.6 & 8.3 \\
\hline Others (respiratory tract, urinary tract, musculo-skeletal, eyes) & 25.9 & 22.7 & 33.3 \\
\hline Medications & $\%$ & $\%$ & $\%$ \\
\hline Cardiovascular agents & 25.9 & 18.2 & 50.0 \\
\hline -Blood pressure lowering substances & 18.5 & 18.2 & 37.5 \\
\hline -Lipid-lowering medications & -18.5 & -0.0 & -12.5 \\
\hline -Anti-coagulants & -11.1 & -0.0 & -20.8 \\
\hline -Others & -3.7 & -0.0 & -12.5 \\
\hline Anti-inflammatory agents (NSAID, cortisone) & 0 & 0 & 4.2 \\
\hline Gut motility regulating substances & 3.7 & 18.2 & 29.2 \\
\hline -Anti-constipation medicine & -0.0 & -13.6 & -12.5 \\
\hline \multicolumn{4}{|l|}{-Anti-diarrheal medicine } \\
\hline -Other Gl regulators (probiotics, fibres) & -7.4 & -4.5 & -4.2 \\
\hline -Proton pump inhibitors (PPI) & -0.0 & -0.0 & -4.2 \\
\hline Antibiotics & 0 & 4.5 & 16.7 \\
\hline -Neurology drugs & 3.7 & 13.6 & 12.5 \\
\hline -Anti-depressants & -3.7 & -13.6 & -0.0 \\
\hline -Hypnotics & -0.0 & -0.0 & -4.2 \\
\hline -Dopamine-agonists & -0.0 & -4.5 & -4.2 \\
\hline -Cholinesterase-inhibitors & -0.0 & -0.0 & -4.2 \\
\hline Others & 18.5 & 27.3 & 29.2 \\
\hline Polypharmacy (5 or more drugs) & 3.7 & 0 & 12.5 \\
\hline Other Gl regulators (probiotics, fibres etc.) & 0 & 4.5 & 8.3 \\
\hline
\end{tabular}

Table 3 Questionnaire details

\begin{tabular}{|c|c|c|c|}
\hline & $\begin{array}{l}\text { The Gastrointestinal Symptoms } \\
\text { Rating Scale - GSRS }\end{array}$ & $\begin{array}{l}\text { The Hospital Anxiety and } \\
\text { Depression Scale - HADS }\end{array}$ & $\begin{array}{l}\text { The Frändin-Grimby } \\
\text { Activity Scale - FGAS }\end{array}$ \\
\hline Subdomains & $\begin{array}{c}\text { Diarrhoea } \\
\text { Constipation } \\
\text { Indigestion } \\
\text { Abdominal pain } \\
\text { Reflux }\end{array}$ & $\begin{array}{l}\text { Anxiety } \\
\text { Depression }\end{array}$ & $\begin{array}{l}\text { Winter season } \\
\text { Summer season }\end{array}$ \\
\hline Nr of questions & 15 & 14 & 6 \\
\hline Scale & $\begin{array}{l}\text { Score } 1=\text { No problems } \\
\text { Score } 7=\text { Severe problems }\end{array}$ & $\begin{array}{l}\text { Score } 0-3 \\
\text { Score } 3 \text { being the highest } \\
\text { symptom frequency }\end{array}$ & Score 1-6 \\
\hline Grading & $\begin{array}{l}\text { No problem }=1 \text { point } \\
\text { Mild }=1-2 \text { points } \\
\text { Moderate }=2-4 \text { points } \\
\text { Severe }=4-7 \text { points }\end{array}$ & $\begin{array}{l}\text { Normal }=0-7 \text { points } \\
\text { Mild }=8-10 \\
\text { Moderate }=11-14 \\
\text { Severe }=15-21\end{array}$ & $\begin{array}{l}\text { No physical activity }=1 \\
\text { Intense regular exercise }=6\end{array}$ \\
\hline Total score & Gut symptoms & Psychological distress & Physical activity \\
\hline
\end{tabular}


ELISA assay CALPRO ${ }^{\circ}$ (CALPRO AS, Lysaker, Norway). Approximately $100 \mathrm{mg}$ of faeces were extracted in $5 \mathrm{~mL}$ of extraction buffer and analysed using a pre-coated 96-well plate provided by the manufacturer. The enzyme reaction was detected at $405 \mathrm{~nm}$. The normal range for faecal calprotectin is defined as $<50 \mu \mathrm{g} / \mathrm{g}$.

\section{Statistical methods \& data analysis}

All data are presented with median and IQR. Shapiro-Wilk test was used to assess normality. The non-parametric Kruskal-Wallis test was used to identify statistical differences between the three study groups, followed by the non-parametric Mann-Whitney U-test for pair-wise comparisons. The Bonferroni-Holm method was used to correct for multiplicity. All statistical analyses were performed using GraphPad Prism version 6 for Mac (GraphPad Software, San Diego California, USA). For visualization of the data biplots of Principal Component Analysis (PCA) were created using R v3.3.0 [30] with functions prcomp and ggbiplot. By convention all values below detection levels were replaced with 0 to facilitate the analysis.

\section{Results}

Intestinal permeability

Assessment of zonulin, an indirect marker of intestinal permeability, showed significantly increased levels among older adults suffering from GI symptoms, compared to general older adults $(p<0.05)$ but not to senior orienteering athletes (Fig. 1).

\section{Psychological distress}

Assessment of overall psychological distress (total HADS score) showed increased levels for both older adults with GI symptoms $(\mathrm{p}<0.05)$ and general older adults $(p<0.05)$ when compared to senior orienteering athletes (Table 1). The level of probable depression was found to be significantly higher among older adults with GI symptoms compared to both general older adults $(p<0.01)$ and senior orienteering athletes $(p<0.001)$ (Fig. 2a). Experience of anxiety showed a different pattern and was found to be significantly higher in both older adults with and without GI symptoms $(\mathrm{p}<0.05)$ compared to senior orienteering athletes (Fig. 2b).

\section{Biomarkers of inflammation and oxidative stress}

Biomarkers of inflammation and oxidative stress were assessed to monitor the inflammatory status of the study participants. For all three populations the CRP levels were found to be within the normal range, $<2 \mathrm{mg} / \mathrm{L}$. Similarly, values of oxidative stress and faecal calprotectin were found to be within the normal range. These data are presented as descriptive values in Table 1.

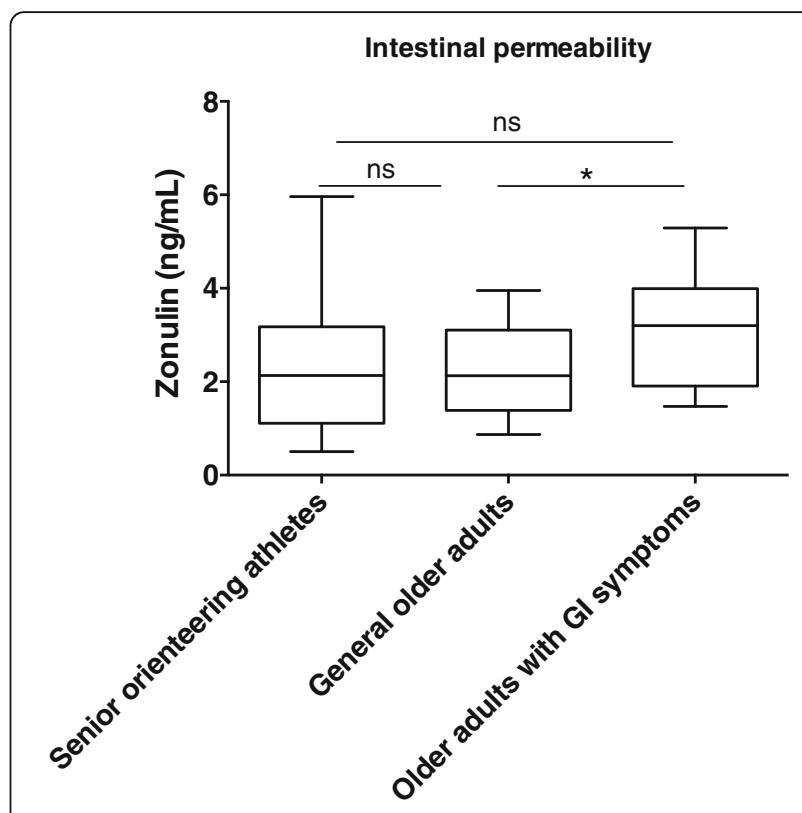

Fig. 1 Intestinal permeability as reflected by plasma zonulin levels in the different groups of older adults. The group of older adults with $\mathrm{Gl}$ symptoms $(n=22)$ had significantly higher plasma zonulin levels than and general older adults $(n=21)$ but not senior orienteering athletes $(n=27)$. No significant difference was observed between senior orienteering athletes and general older adults. ${ }^{* *} p<0.01,{ }^{*} p<0.05$

\section{Comorbidities and medication}

Comorbidities and medical use were reported in the case report forms and are presented in Table 2. The usage of cardiovascular drugs (blood pressure lowering drugs, anti-coagulants etc) was most prominent in all groups. Fifty percent of older adults with GI symptoms reported cardiovascular disease and intake of cardiovascular drugs. Hypertension was identified as the most common condition. Older adults with GI symptoms were also found to consume gut motility regulating substances (29.2\%) to a larger extent compared to the two other study groups. Use of antibiotics was also found to be higher in the study group suffering from GI symptoms. Polypharmacy (defined as intake of five or more medications simultaneously) was found to be more prominent in older adults suffering from GI symptoms (12.5\%) compared to both senior orienteering athletes (3.7\%) and general older adults $(0 \%)$. The levels of zonulin and psychological distress was further found not be influenced by medication and comorbidities when confounding factors were controlled for.

\section{Illustration of the data using principal component analysis}

The PCA revealed a separation between the 3 different study populations, based on GSRS scores and biomarkers (Fig. 3). The highest degree of separation was observed between the senior orienteering athletes and 

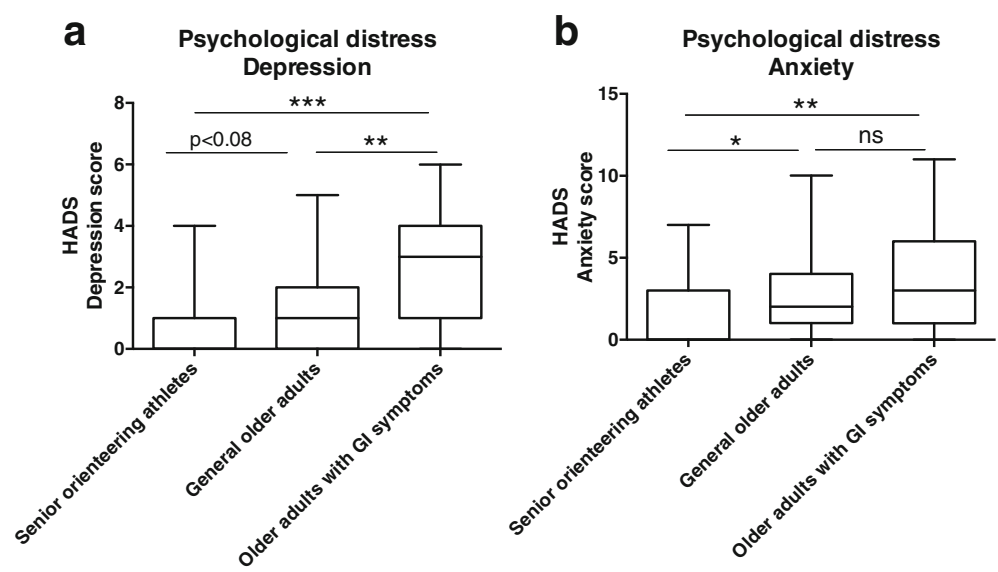

Fig. 2 Depression and anxiety assessed by HADS in the three different populations of older adults. a) The group experiencing Gl symptoms ( $n=24$ ) revealed significantly higher depression scores on the HADS scale than the other two groups. A trend towards a significant difference was observed between the senior orienteering athletes $(n=27)$ and general older adults $(n=22)$. b) Anxiety score was significantly higher in older adults with $G$ l symptoms compared to the senior orienteering athletes. A significantly lower score was seen in senior orienteering athletes when compared to general older adults, with the latter showing no difference compared to group experiencing Gl symptoms. ${ }^{*} p<0.05 ;{ }^{* *} p<0.01 ;{ }^{* * *} p<0.001$, ns $=$ non-significant

older adults with GI symptoms. The general population of older adults were found to clearly overlap the other two populations. This separation is expected and can be explained by the higher GSRS score on the domains diarrhoea and/or constipation among older adults with GI symptoms. An association could be observed between C-reactive protein, ROS and calprotectin. In addition, GI symptoms appear to be associated with zonulin and psychological distress.

\section{Discussion}

To our knowledge this is the first study that investigated the characteristics of self-reported GI symptoms. This is important to facilitate treatment and diagnosis for older adults experiencing moderate GI symptoms. No treatment regimens solely designed for age-associated GI symptoms exist today, and knowledge regarding gut and intestinal barrier function in older adults is poor. As a first step to identify the mechanisms behind age-associated GI symptoms we investigated the relationship between self-reported GI symptoms and intestinal permeability. Furthermore, the impact of GI symptoms on wellbeing was assessed, by investigating the level of psychological distress in relation to experience of gut problems.

As outlined in the results section, we identified that depression-like characteristics were more prominent among older adults suffering from GI symptoms and less common among senior orienteering athletes. The low level of psychological distress among senior orienteering athletes is in line with our previous results [10]. Senior

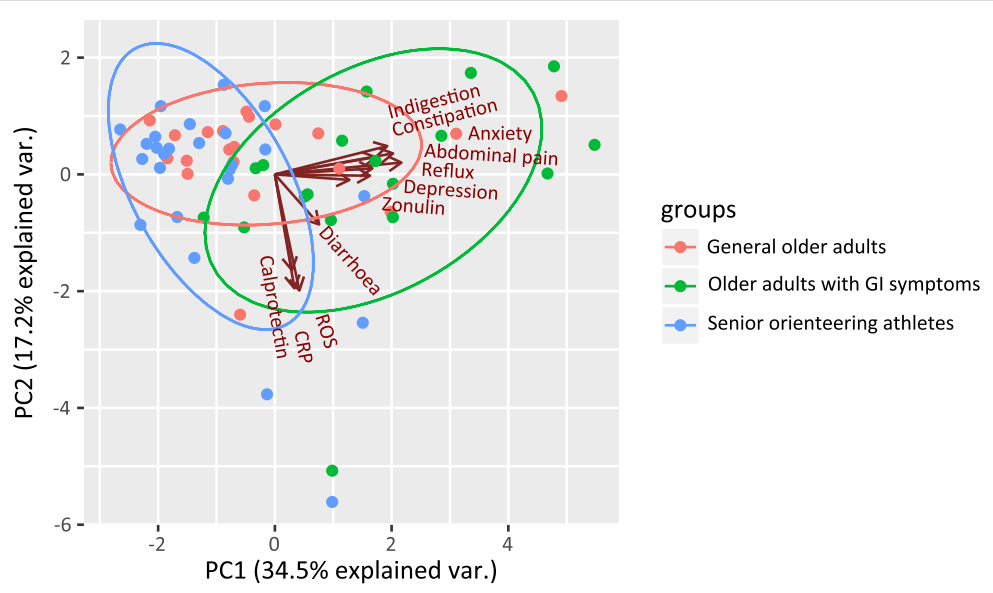

Fig. 3 Principal component analysis displaying the relationship between all investigated biomarkers, HADS domains and GSRS domains in the 3 study populations. Both zonulin and HADS appear associated with the GSRS domains unlike ROS, CRP and calprotectin. The ellipsoid markings cover $95 \%$ of the total populations 
orienteering athletes were also found to suffer from less GI symptoms. Experience of anxiety did not differ between older adults with and without GI symptoms. An increased prevalence of anxiety disorders among older adults has been reported previously [31-33]. However, the levels of psychological distress estimated by HADS were below the cut-off value $(\geq 8)$ for severe anxiety and depression. Hence, indicating that none of the study participants suffered from severe psychological disease. It should also be taken into consideration that the results presented here are based on self-reported data, which relied on the respondents' honesty, accuracy, and interpretation of the question asked.

GI symptoms were found to be associated with elevated levels of plasma zonulin, which indicate that older adults suffering from GI symptoms have increased small intestinal permeability. Moreover, the PCA analysis showed that GI symptoms were found to be associated with psychological distress and zonulin among older adults with GI symptoms. Females $(n=18)$ were further overrepresented among elderly suffering from GI symptoms $(n=24)$. This could reflect the normal distribution of GI symptoms in the population as previous studies report an increased frequency of GI symptoms, such as constipation, among women [34-36]. Stratification for gender did not reveal a significant difference between men and women in regard to GI symptoms, zonulin levels and depression-like characteristics. Anxiety-like characteristics were, on the contrary, found to be significantly higher among elderly men with GI symptoms $(n=6)$. However, this finding could be due to the small study population and further studies using larger sample sets will need to be performed in order to thoroughly elucidate the difference between men and women in relation to psychological distress, GI symptoms and intestinal barrier function.

Increased intestinal permeability is a hallmark in the pathophysiology of chronic inflammatory gastrointestinal diseases, such as Crohn's disease [13]. An altered intestinal permeability has previously been associated with psychiatric disorders such as depression and anxiety [37]. Thus, our results support the notion that intestinal permeability might be an important target for new treatment regimes for age-associated GI symptoms that might have a positive impact on mental wellbeing. Moreover, elderly individuals are known to have a low fibre intake [38] that in addition to a disturbed intestinal motility could alter the gut microbiota and result in a diminished diversity that could have a negative impact on the intestinal barrier function [37]. Recently, we showed that a dietary fibre from yeast was able to attenuate stress-induced hyperpermeability ex vivo across small intestinal tissue from Crohn's disease patients mounted in the Ussing Chamber [39]. Thus, dietary fibres could be a potential therapeutic able to strengthen the intestinal barrier in elderly individuals, however, this needs to be thoroughly investigated in pre-clinical and clinical settings.

Zonulin is the only physiological mediator known to reversibly regulate intestinal permeability by modulating intercellular tight junctions [21, 40]. Circulating zonulin in serum/plasma is considered a useful marker of small intestinal permeability [21, 41] and has been validated using lactulose/mannitol tests [22]. However, zonulin as a marker of small intestinal permeability has been, and is, under debate. Levels of zonulin have been found to fluctuate over time making interpretation of the results difficult [42]. Moreover, a recent study suggests that circulating zonulin might not only be derived from the gastrointestinal tract but may be associated with obesity and hyperlipidaemia $[43,44]$. However, the body mass index (BMI) of the general older adults $(25.6 \pm 4.3 \mathrm{Std})$ and older adults with GI symptoms $(26.7 \pm 5.0 \mathrm{Std})$ included in the present study was normally distributed and no significant differences were observed between the two groups. In addition, stratification of the data revealed no association between cardiovascular disease, including hypertension, and increased zonulin levels. Unfortunately, the BMI was not available for the senior orienteering athletes in the present study. However, the BMI of eleven newly recruited senior orienteering athletes enrolled in an additional study was found to be normally distributed with a mean value of $23.8 \pm 3.2 \mathrm{Std}$. This is in accordance with a recent study showing a lower BMI value of senior athletes compared to general older adults [45]. Hence, these findings indicate that the increased zonulin levels in the present study were not a result of overweight/obesity or cardiovascular disease.

Nevertheless, the findings presented here needs to be confirmed in future studies using more advanced techniques, such as the Ussing Chamber methodology. This will allow for a thorough assessment ex vivo of the intestinal barrier function in elderly using mucosal biopsies $[12,39,46]$ and hence add important information to the results presented here.

Moreover, it is important to point out that older adults with GI symptoms were found to suffer from more comorbidities and did also use more medications. Fifty percent were identified to suffer from cardiovascular disease, were hypertension was found to be the most common condition. A low dose $(75 \mathrm{mg})$ of acetylsalicylic acid (ASA) is commonly prescribed to treat hypertension $[47,48]$. ASA is known to affect the intestinal barrier negatively and induce an increased permeability [49]. In addition, beta-adrenoceptor blocking agents (beta-blockers, mainly used to treat angina pectoris) have been found to decrease bacterial translocation [50]. However, only three participants reported use of ASA 
and two used beta-blockers. Moreover, the median plasma zonulin value in the participants taking medications did not differ from the median of the whole study group. Antibiotic use was also higher among the participants suffering from GI symptoms (16.7\%). Antibiotic use is known to influence the gut microbiota negatively and can cause antibiotic associated diarrhoea [51, 52]. Interestingly, three out of four participants suffered from diarrhoea. However, none of these participants displayed zonulin levels above the median for older adults suffering from GI symptoms. Moreover, it is important to point out that assessment of the gut microbiota was not performed in the present study. Thus, we cannot exclude that the increased intestinal permeability is a consequence of an altered gut flora with an increased number of pathobionts. Nevertheless, assessment of confounding effect showed that medication and comorbidities did not influence intestinal permeability or psychological distress.

In addition, assessment of biomarkers showed no change in inflammatory status in regard to GI symptoms. Thus, confirming that none of the study participants suffered from severe inflammation and infection. It should, however, be noted that in order to thoroughly assess low-grade inflammation pro-inflammatory cytokines, such as IL- 6 , TNF- $\alpha$ and IL- $1 \beta$, should be investigated. Moreover, absence of intestinal inflammation was confirmed by the low calprotectin levels, which fell within the normal range. Thus, indicating that the increased intestinal permeability was not dependent on intestinal inflammation. Hence, our data suggest that moderate GI symptoms area associated with an altered intestinal barrier function and psychological distress. However, in future studies it will be important to perform thorough analysis of the gut microbiota and assess intestinal barrier function using more advanced technology.

\section{Conclusions}

Here we demonstrate that self-reported GI symptoms among older adults are associated with an altered intestinal barrier function as assessed by plasma zonulin levels. Furthermore, both GI symptoms and zonulin levels are associated with increased psychological distress. These findings suggest that even moderate levels of GI symptoms can be reflected in a disturbed intestinal barrier function and increased psychological distress.

\section{Abbreviations}

ASA: Acetylsalicylic acid; CRP: C-reactive protein; FGAS: Frändin-Grimby activity scale; FORT: Free oxygen radicals test; Gl: Gastrointestinal; GSRS: Gastrointestinal symptoms rating scale; HADS: Hospital anxiety and depression scale; PCA: Principal component analysis; ROS: Reactive oxygen species
}

\section{Acknowledgements}

We thank Dr Stephanie Da Silva, Lena Svensson at Linköping University for excellent laboratory work and Frida Fart for valuable help in the organization of data files. In addition, we would like to acknowledge the FibeBiotics EU consortium and collaboration performed within this organization.

\section{Funding}

This work was supported by Bo Rydins stiftelse (Grant ref.: F0514, principal investigator IS), the Knowledge Foundation (Grant ref: 20110225, principal investigator RJB) as well as The Faculty of Medicine and Health at Örebro University. Additional support was granted to ÅVK by Diarrheal Disease Research Centre, Linköping University. The funding bodies were not involved in the study design, collection of data, analysis or interpretation of data, writing of the manuscript or the decision to submit the manuscript for publication.

\section{Availability of data and materials}

All data generated or analysed during this study are included in this published article and its supplementary information files.

\section{Authors' contributions}

LÖL, JPGM, DR2, RJB, ÅVK and IS are responsible for conception and design of the research. JPGM, LÖL, SA, DR1 and IS performed the study. JPGM, LÖL, $S A, D R 1, D R 2, \AA \vee V K, C M L$ and IS took part in the acquisition, analysis and interpretation of both questionnaire data and biological samples. JPGM, LÖL, SA, DR and IS drafted the manuscript. JPGM, LÖL, SA, DR1, DR2, ÅVK, CML, RJB and IS edited and revised the manuscript critically. All authors reviewed and approved the final version of the manuscript and agreed to be accountable for all aspects of the work.

\section{Ethics approval and consent to participate}

The study obtained ethical approval by the Uppsala Regional Ethics Review Board (Dnr. 2012/309, 2013/37 and 2015/357). All procedures were carried out in accordance with the declaration of Helsinki and written informed consent was acquired from all participants before study start.

\section{Consent for publication}

Not Applicable.

\section{Competing interests}

The authors declare that they have no competing interests.

\section{Publisher's Note}

Springer Nature remains neutral with regard to jurisdictional claims in published maps and institutional affiliations.

\section{Author details}

${ }^{1}$ Nutrition Gut Brain Interactions Research Centre, Department of Medical Sciences, Faculty of Medicine and Health, Örebro University, Örebro, Sweden. ${ }^{2}$ Nutrition and Physical Activity Research Centre, Department of Medical Sciences, Faculty of Medicine and Health, Örebro University, Örebro, Sweden. ${ }^{3}$ Department of Clinical and Experimental Medicine, Linköping University, Linköping, Sweden.

Received: 1 July 2017 Accepted: 12 March 2018

Published online: 20 March 2018

\section{References}

1. Cohen JE. Human population: the next half century. Science. 2003; 302(5648):1172-5.

2. Algilani S, Ostlund-Lagerstrom L, Kihlgren A, Blomberg K, Brummer RJ, Schoultz I. Exploring the concept of optimal functionality in old age. Multidiscip Healthc. 2014;7:69-79.

3. Bosshard W, Dreher R, Schnegg JF, Bula CJ. The treatment of chronic constipation in elderly people: an update. Drugs Aging. 2004;21(14):911-30.

4. Kinnunen O. Study of constipation in a geriatric hospital, day hospital, old people's home and at home. Aging (Milano). 1991;3(2):161-70.

5. Scallan E, Majowicz SE, Hall G, Banerjee A, Bowman CL, Daly L, Jones $T$, Kirk MD, Fitzgerald $M$, Angulo FJ. Prevalence of diarrhoea in the community in Australia, Canada, Ireland, and the United States. Int J Epidemiol. 2005;34(2):454-60.

6. Talley NJ, O'Keefe EA, Zinsmeister AR, Melton LJ. 3rd: prevalence of gastrointestinal symptoms in the elderly: a population-based study. Gastroenterology. 1992;102(3):895-901. 
7. Pilotto A, Franceschi M, Vitale D, Zaninelli A, Di Mario F, Seripa D, Rengo F Firi, Investigators SP. The prevalence of diarrhea and its association with drug use in elderly outpatients: a multicenter study. Am J Gastroenterol. 2008;103(11):2816-23.

8. Eckerblad J, Theander K, Ekdahl A, Unosson M, Wirehn AB, Milberg A, Krevers B, Jaarsma T. Symptom burden in community-dwelling older people with multimorbidity: a cross-sectional study. BMC Geriatr. 2015;15:1.

9. James I, Blomberg K, Kihlgren A. A meaningful daily life in nursing homes a place of shelter and a space of freedom: a participatory appreciative action reflection study. BMC Nurs. 2014;13:19.

10. Ostlund-Lagerstrom L, Blomberg K, Algilani S, Schoultz M, Kihlgren A, Brummer RJ, Schoultz I. Senior orienteering athletes as a model of healthy aging: a mixed-method approach. BMC Geriatr. 2015;15:76.

11. Gareau MG. Microbiota-gut-brain axis and cognitive function. Adv Exp Med Biol. 2014;817:357-71.

12. Bednarska O, Walter SA, Casado-Bedmar M, Strom M, Salvo-Romero E, Vicario M, Mayer EA, Keita AV. Vasoactive intestinal polypeptide and mast cells regulate increased passage of colonic Bacteria in patients with irritable bowel syndrome. Gastroenterology. 2017;153(4):948-60. e943

13. Salim SY, Soderholm JD. Importance of disrupted intestinal barrier in inflammatory bowel diseases. Inflamm Bowel Dis. 2011:17(1):362-81.

14. Vancamelbeke $M$, Vermeire $S$. The intestinal barrier: a fundamental role in health and disease. Expert Rev Gastroenterol Hepatol. 2017;11(9):821-34.

15. Bischoff SC, Barbara G, Buurman W, Ockhuizen T, Schulzke JD, Serino M, Tilg $\mathrm{H}$, Watson A, Wells JM. Intestinal permeability-a new target for disease prevention and therapy. BMC Gastroenterol. 2014;14:189.

16. Wells JM, Brummer RJ, Derrien M, MacDonald TT, Troost F, Cani PD, Theodorou V, Dekker J, Meheust A, de Vos WM, et al. Homeostasis of the gut barrier and potential biomarkers. Am J Physiol Gastrointest Liver Physiol. 2017;312(3):G171-93.

17. Suzuki T. Regulation of intestinal epithelial permeability by tight junctions. Cell Mol Life Sci. 2013;70(4):631-59.

18. Forsyth CB, Shannon KM, Kordower JH, Voigt RM, Shaikh M, Jaglin JA, Estes JD, Dodiya HB, Keshavarzian A. Increased intestinal permeability correlates with sigmoid mucosa alpha-synuclein staining and endotoxin exposure markers in early Parkinson's disease. PLoS One. 2011:6(12):e28032.

19. Zhang R, Miller RG, Gascon R, Champion S, Katz J, Lancero M, Narvaez A, Honrada R, Ruvalcaba D, McGrath MS. Circulating endotoxin and systemic immune activation in sporadic amyotrophic lateral sclerosis (SALS). J Neuroimmunol. 2009;206(1-2):121-4.

20. Wang A, Keita AV, Phan V, McKay CM, Schoultz I, Lee J, Murphy MP, Fernando M, Ronaghan N, Balce D, et al. Targeting mitochondria-derived reactive oxygen species to reduce epithelial barrier dysfunction and colitis. Am J Pathol. 2014;184(9):2516-27.

21. Wang W, Uzzau S, Goldblum SE, Fasano A. Human zonulin, a potential modulator of intestinal tight junctions. J Cell Sci. 2000;113(Pt 24):4435-40.

22. Sapone A, de Magistris L, Pietzak M, Clemente MG, Tripathi A, Cucca F, Lampis R, Kryszak D, Carteni M, Generoso M, et al. Zonulin upregulation is associated with increased gut permeability in subjects with type 1 diabetes and their relatives. Diabetes. 2006;55(5):1443-9.

23. Svedlund J, Sjodin I, Dotevall G. GSRS-a clinical rating scale for gastrointestinal symptoms in patients with irritable bowel syndrome and peptic ulcer disease. Dig Dis Sci. 1988;33(2):129-34.

24. Chaplin A, Curless R, Thomson R, Barton R. Prevalence of lower gastrointestinal symptoms and associated consultation behaviour in a British elderly population determined by face-to-face interview. $\mathrm{Br} J \mathrm{Gen}$ Pract. 2000:50(459):798-802.

25. Zuchelli T, Myers SE. Gastrointestinal issues in the older female patient. Gastroenterol Clin N Am. 2011;40(2):449-66. x

26. Snaith RP, Zigmond AS. The hospital anxiety and depression scale. Br Med J (Clin Res Ed). 1986;292(6516):344.

27. Roberts MH, Fletcher RB, Merrick PL. The validity and clinical utility of the hospital anxiety and depression scale (HADS) with older adult new Zealanders. Int Psychogeriatr. 2014;26(2):325-33.

28. Frändin K, Grimby G. Assessment of physical activity, fitness and performance in 76-year-olds. Scand J Med Sci Sports. 2007;4(1):41-6.

29. Palmieri B, Sblendorio V. Oxidative stress tests: overview on reliability and use. Part II. Eur Rev Med Pharmacol Sci. 2007;11(6):383-99.

30. R: A language and environment for statistical computing: R Core team. R Foundation for Statistical Computing. Vienna. 2016. [http://www.rproject.org].
31. Samuelsson G, McCamish-Svensson C, Hagberg B, Sundstrom G, Dehlin $\mathrm{O}$. Incidence and risk factors for depression and anxiety disorders: results from a 34-year longitudinal Swedish cohort study. Aging Ment Health. 2005:9(6):571-5.

32. Schaub RT, Linden M. Anxiety and anxiety disorders in the old and very old-results from the berlin aging study (BASE). Compr Psychiatry. 2000;41(2 Suppl 1):48-54.

33. van Balkom AJ, Beekman AT, de Beurs E, Deeg DJ, van Dyck R, van Tilburg W. Comorbidity of the anxiety disorders in a community-based older population in the Netherlands. Acta Psychiatr Scand. 2000;101(1):37-45.

34. Walter S, Hallbook O, Gotthard R, Bergmark M, Sjodahl R. A populationbased study on bowel habits in a Swedish community: prevalence of faecal incontinence and constipation. Scand J Gastroenterol. 2002;37(8):911-6.

35. Higgins PD, Johanson JF. Epidemiology of constipation in North America: a systematic review. Am J Gastroenterol. 2004:99(4):750-9.

36. Wald A, Scarpignato C, Mueller-Lissner S, Kamm MA, Hinkel U, Helfrich I, Schuijt C, Mandel KG. A multinational survey of prevalence and patterns of laxative use among adults with self-defined constipation. Aliment Pharmacol Ther. 2008;28(7):917-30

37. Kelly JR, Kennedy PJ, Cryan JF, Dinan TG, Clarke G, Hyland NP. Breaking down the barriers: the gut microbiome, intestinal permeability and stressrelated psychiatric disorders. Front Cell Neurosci. 2015:9:392.

38. Donini LM, Savina C, Cannella C. Nutrition in the elderly: role of fiber. Arch Gerontol Geriatr. 2009;49(Suppl 1):61-9.

39. Ganda Mall JP, Casado-Bedmar M, Winberg ME, Brummer RJ, Schoultz I, Keita AV. A beta-glucan-based dietary Fiber reduces mast cell-induced Hyperpermeability in ileum from patients with Crohn's disease and control subjects. Inflamm Bowel Dis. 2017;24(1):166-78.

40. Fasano A. Regulation of intercellular tight junctions by zonula occludens toxin and its eukaryotic analogue zonulin. Ann N Y Acad Sci. 2000;915:214-22.

41. Smecuol E, Sugai E, Niveloni S, Vazquez $H$, Pedreira S, Mazure $R$ Moreno ML, Label M, Maurino E, Fasano A, et al. Permeability, zonulin production, and enteropathy in dermatitis herpetiformis. Clin Gastroenterol Hepatol. 2005;3(4):335-41.

42. Vojdani A, Vojdani E, Kharrazian D. Fluctuation of zonulin levels in blood vs stability of antibodies. World J Gastroenterol. 2017;23(31):5669-79.

43. Ohlsson B, Orho-Melander M, Nilsson PM. Higher levels of serum Zonulin may rather be associated with increased risk of obesity and hyperlipidemia, than with gastrointestinal symptoms or disease manifestations. Int J Mol Sci. 2017;18(3):1-13.

44. Moreno-Navarrete JM, Sabater M, Ortega F, Ricart W, Fernandez-Real JM. Circulating zonulin, a marker of intestinal permeability, is increased in association with obesity-associated insulin resistance. PLoS One. 2012;7(5):e37160.

45. Condello G, Capranica L, Stager J, Forte R, Falbo S, Di Baldassarre A, SeguraGarcia C, Pesce C. Physical activity and health perception in aging: do body mass and satisfaction matter? A three-path mediated link. PLoS One. 2016; 11(9):e0160805.

46. Keita AV, Gullberg E, Ericson AC, Salim SY, Wallon C, Kald A, Artursson P, Soderholm JD. Characterization of antigen and bacterial transport in the follicle-associated epithelium of human ileum. Lab Investig. 2006;86(5):504-16.

47. Hansson L, Zanchetti A, Carruthers SG, Dahlof B, Elmfeldt D, Julius S, Menard J, Rahn KH, Wedel H, Westerling S. Effects of intensive blood-pressure lowering and low-dose aspirin in patients with hypertension: principal results of the hypertension optimal treatment (HOT) randomised trial. HOT study group. Lancet. 1998;351(9118):1755-62.

48. Ittaman SV, VanWormer JJ, Rezkalla SH. The role of aspirin in the prevention of cardiovascular disease. Clin Med Res. 2014;12(3-4):147-54.

49. Bjarnason I, Williams P, Smethurst P, Peters TJ, Levi AJ. Effect of nonsteroidal anti-inflammatory drugs and prostaglandins on the permeability of the human small intestine. Gut. 1986;27(11):1292-7.

50. Perez-Paramo M, Munoz J, Albillos A, Freile I, Portero F, Santos M, OrtizBerrocal J. Effect of propranolol on the factors promoting bacterial translocation in cirrhotic rats with ascites. Hepatology. 2000;31(1):43-8.

51. Tulstrup MV, Christensen EG, Carvalho V, Linninge C, Ahrne S, Hojberg O, Licht TR, Bahl MI. Antibiotic treatment affects intestinal permeability and gut microbial composition in Wistar rats dependent on antibiotic class. PLoS One. 2015;10(12):e0144854.

52. Wistrom J, Norrby SR, Myhre EB, Eriksson S, Granstrom G, Lagergren L, Englund G, Nord CE, Svenungsson B. Frequency of antibiotic-associated diarrhoea in 2462 antibiotic-treated hospitalized patients: a prospective study. J Antimicrob Chemother. 2001;47(1):43-50. 